\title{
PHAONIA ROBINEAU-DESVOIDY (DIPTERA, MUSCIDAE, PHAONIINAE). I. DESCRIÇÃO DE CINCO ESPÉCIES NOVAS DA REGIÃO NEOTROPICAL ${ }^{1}$
}

\author{
Sônia Maria Prevedello Coelho ${ }^{2}$
}

\begin{abstract}
Phaonla Robineau-Desvoidy (Diptera, Muscidae, Phaoninae). I. DESCRIPTION of Five NLW SPECILS IROM NLotropical REgion. Phaonia boliviana sp.n., Phaonia equatorialis sp.n., Phaonia punoensis sp.n., Phaonia quercus sp.n. and Phaonia soratiensis sp.n. from Neotropical Region are described and illustrated. KEY WORDS. Muscidae, Phaonia, Neotropical Region, new species
\end{abstract}

Para revisão do gênero Phaonia Robineau-Desvoidy, 1830 da Região Neotropical foram estudados 1500 espécimes, este número representando cerca de $90 \%$ das espécies listadas no catálogo das espécies neotropicais (CARVALHO et al. 1993).

Este primeiro trabalho trata das espécies novas encontradas, as quais são descritas e ilustradas.

O material estudado foi emprestado pelas seguintes instituições (curadores entre parênteses): CNC - Canadian National Collection, Ottawa, Canadá (Dr. J.R. Vockeroth); SMT - Staatliches Museum für Tierkunde, Dresden, Alemanha (Dr. U. Kallweit); ZMHU - Museum für Naturkunde, Humboldt - Universität, Berlim, Alemanha (Dr. H. Schumann).

Para terminologia e abreviaturas, foram seguidos MCALPINE (1981) e CARVALHO (1989).

\section{Phaonia boliviana sp.n.}

Figs 1-2

Material-tipo. Holótipo fêmea etiquetado: "Bolivia/ Coroico"; "Type" [etiqueta avermelhada]; "Phaonia/ venicurva/ type Stein \$/ det. Stein"; "Zool. Mus./ Berlin"; "Paralectotipo"; "Phaonia venicurva/ (Stein, 1904)/ S.M.P. Coelho det. 94"; "Holotipo" [etiqueta vermelha com uma linha preta no bordo]; "Phaonia boliviana/ sp.n./ S.M.P. Coelho det." (ZMHU). Em estado razoável, com o tegumento untoso; asa direita danificada à altura da veia transversal anterior até a veia costal; faltando o terceiro flagelômero esquerdo; abdome dissecado e em tubinho com glicerina.

Etimologia. O nome específico é alusivo à Bolívia.

1) Contribuição número 1051 do Departamento de Zoologia, Universidade Federal do Paraná.

2) Rua Professor João Kochaki 375. 81520-200 Curitiba, Paraná, Brasil. 

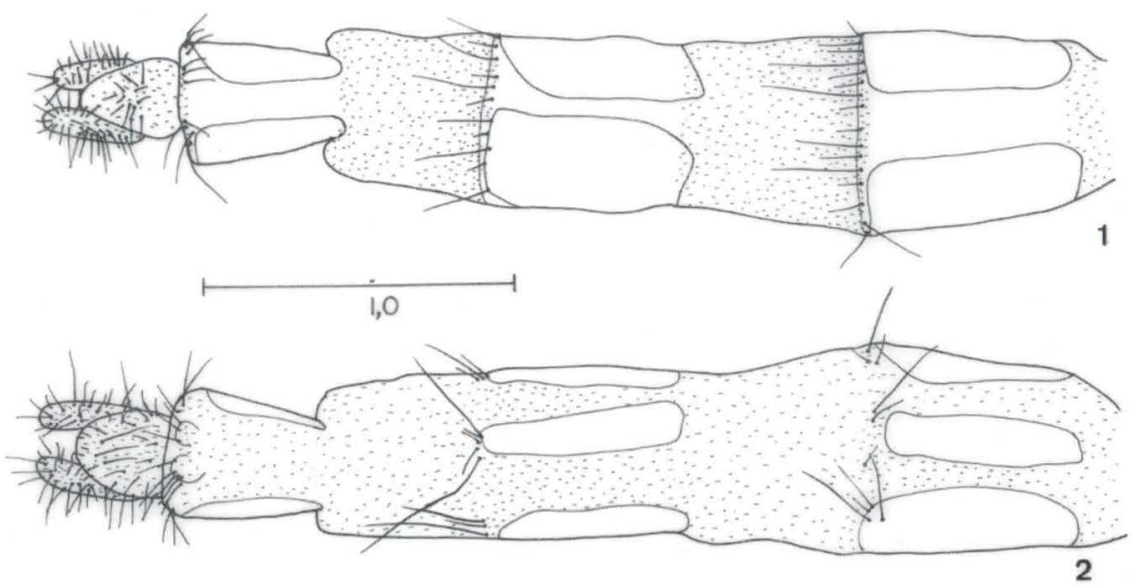

Figs 1-2. Phaonia boliviana sp.n.. (1) Ovipositor, vista dorsal; (2) ovipositor, vista ventral. Escalas em milimetros.

Considerações. Um síntipo fêmea de P. venicurva (Stein, 1904) acima citado é designado holótipo de Phaonia boliviana sp.n.

Diagnose. Coloração geral castanho-escura à negra; de 2:4; acr 0:1; espiráculo posterior na margem PV sem cílios; veia $\mathrm{M}_{1+2}$ nitidamente curva em direção à R4+5; tíbia I na face A com duas cerdas medianas; tíbia II na face A nua; fêmur III na face A sem cerda pré-apical; tíbia III na face A com uma cerda sub-basal. Fêmea: ovipositor sem microtriquias nos tergitos, esternitos VI e VII e entre os tergitos; cercos, epiprocto e hipoprocto com cerdas fortes (Figs 1, 2).

Descrição. Coloração geral castanho-escura à negra. Frontália, lúnula, probóscide, palpo e antena castanho-escuros. Parafrontália, parafaciália, faciália e gena castanho-escuras com leve polinosidade prateada. Tórax castanho-escuro; união do úmero com escuto amarelado. Caliptras esbranquiçadas; balancim amarelado. Asa acastanhada com leve escurecimento nas veias transversais anterior e posterior. Pernas castanhas, com tíbia mediana, fêmur e tíbia posterior, amarelados; pulvilos esbranquiçados. Abdome negro, com ápice do tergito V amarelado.

Macho. Desconhecido.

Fêmea. $8,08 \mathrm{~mm}$, asa $7,50 \mathrm{~mm}$.

Cabeça. Olhos separados por um espaço cerca de 0,48 da largura da cabeça no nível da lúnula; facetas antero-internas pouco diferenciadas. Triângulo ocelar com duas cerdas fortes, proclinadas e divergentes. Cerdas frontais em número de 6-7 pares, dois últimos reclinados. Vte fortes, divergentes e semelhantes às vti que são convergentes. Antena inserida abaixo da metade do olho, com flagelo cerca de 3 vezes o comprimento do pedicelo; arista plumosa. Parafaciália estreita, no nível do ápice do pedicelo cerca de $2 / 5$ da gena no nível inferior do olho. Palpo claviforme.

Tórax: dc 2:4; acr 0:1, fraca em relação a dc; três cerdas umerais; uma pós-umeral; uma prs; duas ia; pra forte, semelhante a npl anterior; duas sa, posterior inconspícua; duas psa, posterior maior; notopleura com esparsos cílios de 
revestimento; npl posterior cerca de 2/3 da anterior. Escutelo com um par de cerda basal; um pré-apical fraco e um apical forte, semelhante ao basal. Duas cerdas pro-episternais, anterior fraca e duas pro-epimerais semelhantes. Ctpl 1:2. Catepimero, meron e espiráculo posterior na margem PV sem cílios. Caliptra inferior cerca de 1,6 vezes a superior. Asa com nódulo radial com 2-3 cílios na face ventral; veia $\mathrm{M}_{1+2}$ nitidamente curva em direção à $\mathrm{R}_{4+5}$. Fêmur I nas faces $\mathrm{D}, \mathrm{AD}$ e $\mathrm{AV}$ com uma série de cerdas em toda a face. Tíbia na face A com duas cerdas medianas. Tarso com garras e pulvilos curtos, menores que o comprimento do tarsômero V. Fêmur II na face V com quatro cerdas basais fortes; faces D sem cerda e PD com duas pré-apicais. Tíbia na face P com três cerdas medianas. Tarso como no par anterior. Fêmur III na face AD com uma série de cerdas em toda a face; face AV com 5-6 cerdas fortes no terço apical; faces D com duas cerdas e PD com uma fraca, pré-apicais. Tíbia na face A com três cerdas, uma sub-basal e duas medianas; face AV com 2-3 cerdas medianas e fracas em relação as anteriores; calcar forte, inserido no quinto apical. Tarso como no par anterior.

Abdome. Esternito I nu.

Ovipositor. Tubular, longo, semelhante ao comprimento do abdome; sem microtríquias nos tergitos, esternitos VI e VII e entre os tergitos; cercos, epiprocto e hipoprocto com cerdas fortes (Figs 1,2).

Distribuição geográfica. Bolívia (La Paz).

\section{Phaonia equatorialis sp.n.}

Figs 3-8

Material-tipo. Holótipo macho etiquetado: "Cerro Tinajillas/ Azuay, Ecuador/ 15.III.1965/3200m, L. Pena"; "Holotipo" [etiqueta vermelha com uma linha preta no bordo]; "Phaonia equatorialis/ sp.n./ S.M.P. Coelho det." (CNC). Em bom estado, faltando perna mediana direita.

Diagnose. Coloração geral negra; olhos amplamente ciliados; dc 2:4; acr $0: 1$; espiráculo posterior na margem PV sem cílios; veia $\mathrm{M}_{1+2}$ nitidamente curva em direção à $\mathrm{R}_{4+5}$; tíbia I na face $\mathrm{A}$ com uma cerda mediana; tíbia II na face $\mathrm{A}$ com uma cerda sub-mediana; fêmur III na face A com uma cerda pré-apical; tíbia III na face A sem cerda sub-basal. Macho: parâmero com a face ventral pouco recurvada; gonópodo com a região anterior não ultrapassando a largura do parâmero e face ventral recurvada (Fig. 6).

Etimologia. O nome específico é alusivo ao Equador.

Descrição. Coloração geral negra com leve polinosidade cinzenta. Frontália, lúnula, antena, probóscide e palpo castanho-escuros a negros. Parafrontália, parafaciália, faciália e gena castanho-escuras à negras com polinosidade prateada. Tórax negro. Escuto com quatro listras, duas medianas e duas laterais, pouco visíveis. Caliptras esbranquiçadas. Balancim amarelado. Asa acastanhada com máculas pouco visíveis nas veias transversais anterior e posterior. Pernas castanho-escuras com tíbias posteriores mais claras; pulvilos esbranquiçados. Abdome negro com leve polinosidade cinzenta. 


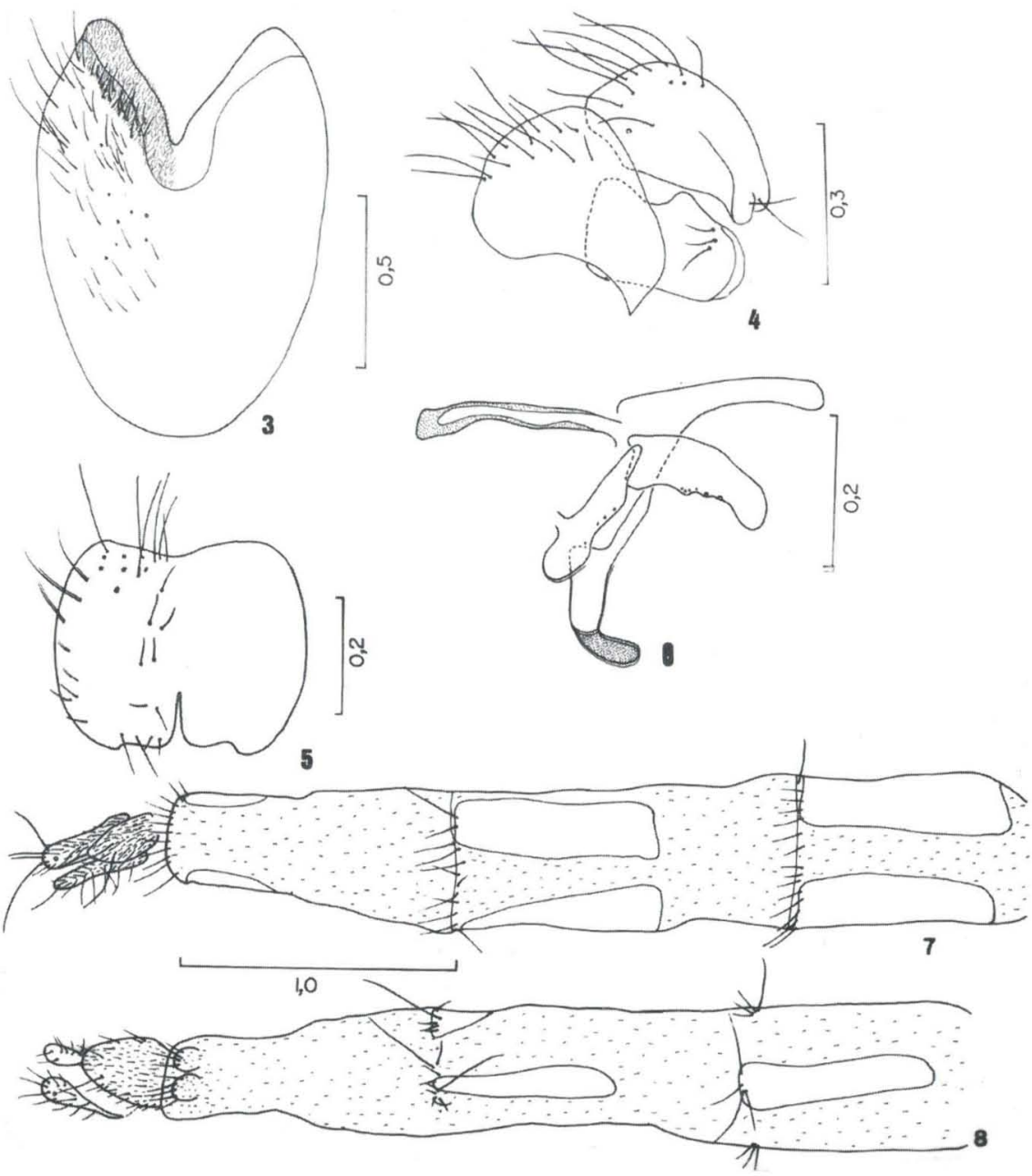

Figs 3-8. Phaonia equatorialis sp.n.. (3) Esternito V, vista posterior; (4) epândrio, cercos e surstilo, vista lateral; (5) cercos, vista posterior; (6) edeago e acessórios, vista lateral; (7) ovipositor, vista dorsal; (8) ovipositor, vista ventral. Escalas em milimetros.

Macho. 7,42-8,08mm, asa 6,67-7,83mm.

Cabeça. Olhos unidos, com muitos cílios curtos, afastados por um espaço que mede à altura do ocelo anterior $0,26 \mathrm{~mm}$; facetas antero-internas pouco diferenciadas. Cerdas frontais em número de 4-5 pares iniciados no nível da lúnula e terminados no terço médio da frontália. Antena inserida ao nível da metade do olho, com flagelo cerca de duas vezes o comprimento do pedicelo; arista plumosa. Parafaciália estreita, no nível do ápice do pedicelo cerca de $2 / 3$ da gena no nível inferior do olho. Palpo claviforme. 
Tórax. de 2:4; acr 0:1, fraca em relação a dc; 3-4 cerdas umerais; uma pós-umeral; uma prs; duas ia; pra forte, semelhante a $\mathbf{n p l}$ anterior; duas sa, posterior inconspícua; duas psa, posterior maior; notopleura com esparsos cílios de revestimento; npl posterior cerca de 1/2 da anterior. Escutelo com dois pares de cerdas basais, anterior medíocre; um pré-apical e um apical fortes, semelhantes ao basal posterior. Duas cerdas pro-episternais, anterior fraca e duas pro-epimerais semelhantes. Ctpl 1:2. Catepimero com cílios. Meron e espiráculo posterior na margem PV sem cílios. Caliptra inferior cerca de 1,6 vezes a superior. Asa com nódulo radial com 1-2 cílios na face ventral; veia $\mathrm{M}_{1+2}$ nitidamente curva em direção à $\mathrm{R}_{4+5}$; veia transversal posterior recurvada. Fêmur I nas faces $\mathrm{D}, \mathrm{AD}$ e $\mathrm{AV}$ com uma série de cerdas em toda a face. Tíbia na face A com uma cerda mediana. Tarso com garras e pulvilos longos, maiores que o comprimento do tarsômero V. Fêmur II na face V com três cerdas basais fortes; faces D com uma cerda fraca e PD com duas fortes, pré-apicais e oblíquas ao plano do fêmur. Tíbia na face P com duas cerdas medianas; face A com uma cerda sub-mediana. Tarso como no par anterior. Fêmur III na face AD com uma série de cerdas em toda face; face AV com 5-6 cerdas no terço apical; face A com uma cerda pré-apical; faces D com duas cerdas e PD com 1-2, fracas, pré-apicais e oblíquas ao plano do fêmur. Tíbia nas faces A com duas cerdas e AV com 2-3, medianas, aquelas mais fortes; calcar forte, inserido no quinto apical. Tarso como no par anterior.

Abdome. Esternito I nu.

Terminália. Esternito V oval, com cerdas na metade apical (Fig. 3); placa cercal quadrangular, elevada superiormente e bifurcada ventralmente; surstilo pouco mais longo que a placa cercal, com cílios pré-apicais (Figs 4, 5); apódema do edeago estreito; parâmero com a face ventral pouco recurvada; gonópodo com a região anterior não ultrapassando a largura do parâmero e face ventral recurvada (Fig. 6).

Fêmea. 7,00-9,17mm, asa 7,33-9,50mm.

Semelhante ao macho diferindo no que segue: olhos separados por um espaço cerca de 0,48 da largura da cabeça no nível da lúnula. Triângulo ocelar com duas cerdas fortes, proclinadas e divergentes. Cerdas frontais em número de 6-7 pares, dois últimos reclinados. Vte fortes, divergentes e menores que vti que são convergentes. Parafaciália estreita, no nível do ápice do pedicelo cerca de $3 / 4$ da gena no nível inferior do olho. Antena inserida ao nivel da metade do olho.

Ovipositor. Tubular, longo, semelhante ao comprimento do abdome; microtríquias presentes nas membranas e esternito VIII (Figs 7, 8).

Material examinado. Parátipos: ColômBIA, Caldas: $5^{\circ} 5^{\prime} \mathrm{N}-76^{\circ} 28^{\prime} \mathrm{W}$, 3350m, 1 fềmea, 4.IV.1973, J. Helava leg. (CNC); Cauca: Páramo de Puracé, 3400m, 1 fêmea, 26.II.1970, D.M. Wood leg. (CNC). EQUADor, Carchi: Cerro Pelado, 3200m, 1 macho e 1 fêmea, 25.VI.1965, L. Pena leg. (CNC); Azuay: Cerro Tinajillas, 3200m, 1 macho e 2 fêmeas, 15.III.1965, L. Pena leg. (CNC).

Distribuição geográfica. ColôMBIA (Caldas: Cauca), EQUADOR (Carchi: Azuay). 


\section{Phaonia punoensis sp.n.}

Figs 9-10

Material-tipo. Holótipo fêmea etiquetado: "Peru - Puno/ 11.VI.09/ Titicaca See"; "Coll. W. Schnuse/ 1911-3"; "Staatl. Museum für/ Tierkunde Dresden"; "Phaonia/ punctinervis/ Stein, 1911" [etiqueta manuscrita]; "Paralectotipo"; "Phaonia punctinervis/ Stein, 1911/ S.M.P. Coelho det. 94"; "Holotipo" [etiqueta vermelha com uma linha preta no bordo]; "Phaonia punoensis/ sp.n./ S.M.P. Coelho det." (SMT). Em estado razoável, faltando os terceiros artículos antenais, pernas anterior direita e mediana esquerda e os tarsos posteriores; borda das asas pouco danificadas; abdome dissecado e em tubinho com glicerina.

Etimologia. O nome específico refere-se à localidade-tipo.

Considerações. Um dos síntipos fềmea de Phaonia punctinervis Stein, 1911 é Phaonia punoensis sp.n. e é designado holótipo desta.

Diagnose. Coloração geral castanho-escura com ápice do tergito $\mathrm{V}$ amarelado; de 2:3; acr 0:1; espiráculo posterior na margem PV sem cílios; veia $\mathrm{M}_{1+2}$ nitidamente curva em direção à R4+5; tíbia I na face $\mathrm{A}$ com duas cerdas medianas $\mathrm{e}$ na face P com uma sub-mediana; tíbia II nas faces P com duas cerdas e A com uma, medianas. Fêmea: ovipositor com microtríquias nas membranas intersegmentares e segmentar VIII, tergito VIII e esternito VIII (Figs 9, 10).

Descrição. Coloração geral castanho-escura com polinosidade cinzenta. Frontália, lúnula e probóscide castanho-escuras. Parafrontália, parafaciália, faciália e gena castanho-escuras com polinosidade prateada. Palpo castanho-escuro. Antena com escapo e pedicelo castanho-escuros. Tórax castanho-escuro. Escuto com quatro listras, duas medianas e duas laterais, mais visíveis pré-suturalmente. Caliptras esbranquiçadas; balancim amarelado. Asa acastanhada com máculas castanho-escuras pouco nítidas nas veias transversais anterior e posterior. Pernas castanhas com tíbias anteriores, fêmures e tíbias medianas e posteriores castanho-claros; tarsos mais escuros; pulvilos esbranquiçados. Abdome castanho-escuro com ápice do tergito $\mathrm{V}$ amarelado e polinosidade cinzenta alternada, dando aspecto xadrez.

Macho. Desconhecido.

Fêmea. $6,00 \mathrm{~mm}$, asa $5,75 \mathrm{~mm}$.

Cabeça. Olhos separados, com esparsos cílios curtos, afastados por um espaço cerca de 0,42 da largura da cabeça no nível da lúnula; facetas antero-internas pouco diferenciadas. Triângulo ocelar com duas cerdas fortes, proclinadas e divergentes. Cerdas frontais em número de cinco pares, dois últimos reclinados. Parafrontália com uma série de pequenas cerdas na região mediana, paralelas as frontais. Vte fortes, divergentes e menores que vti que são convergentes. Parafaciália estreita, no nível do ápice do pedicelo cerca de $1 / 2$ da gena no nível inferior do olho. Antena inserida acima da metade do olho; arista plumosa. Palpo claviforme.

Tórax. dc 2:3; acr 0:1, fraca em relação a dc; três cerdas umerais; uma pós-umeral; uma prs; duas ia; pra forte, semelhante a $\mathbf{n p l}$ anterior; duas sa, posterior inconspícua; duas psa, posterior maior; notopleura com esparsos cílios de revestimento; npl posterior cerca de $2 / 3$ da anterior. Escutelo com dois pares de 

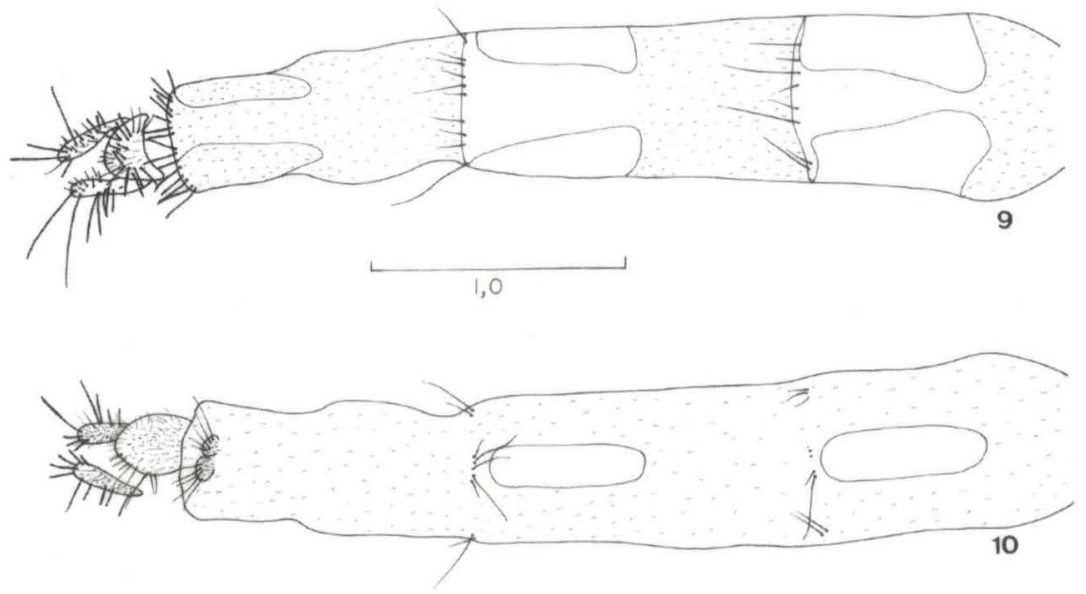

Figs 9-10. Phaonia punoensis sp.n.. (9) Ovipositor, vista dorsal; (10) ovipositor, vista ventral. Escalas em milimetros.

cerdas basais, anterior medíocre; um pré-apical e um apical forte, semelhante ao basal posterior. Duas cerdas pro-episternais, anterior fraca e duas pro-epimerais, anterior forte. Ctpl 1:2. Catepimero, meron e espiráculo posterior na margem PV sem cílios. Caliptra inferior cerca de 1,4 vezes a superior. Asa com nódulo radial com 1 cílio na face dorsal e, 1-2 na face ventral; veia $M_{1+2}$ nitidamente curva em direção à $\mathrm{R}_{4+5}$, veia transversal posterior recurvada. Fêmur I nas faces $\mathrm{D}, \mathrm{AD}$ e $\mathrm{AV}$ com uma série de cerdas em toda a face. Tíbia na face A com duas cerdas medianas; face $\mathrm{P}$ com uma cerda sub-mediana fraca. Tarso com garras e pulvilos curtos, menores que o comprimento do tarsômero V. Fêmur II na face V com quatro cerdas basais fortes; face PD com duas cerdas pré-apicais e oblíquas ao plano do fêmur. Tíbia nas faces $\mathrm{P}$ com duas cerdas e A com uma, medianas. Tarso como no par anterior. Fêmur III na face AD com uma série de cerdas em toda face; face AV com 4-5 cerdas no terço apical; faces D com duas cerdas e PD com uma, fracas, pré-apicais e oblíquas ao plano do fêmur. Tíbia nas faces A e AV com duas cerdas medianas, aquelas mais fortes; calcar forte, inserido no quinto apical. Tarso como no par anterior.

Abdome. Esternito I nu.

Ovipositor. Tubular, longo, semelhante ao comprimento do abdome; microtríquias presentes nas membranas intersegmentares e segmentar VIII, tergito VIII e esternito VIII (Figs 9, 10).

Distribuição geográfica. PERU (Puno)

\section{Phaonia quercus sp.n.}

Figs $11-16$

Material-tipo. Holótipo macho, etiquetado: “Avispas, Madre/ de Dios, PERU/ 1-15.X.1962/ L. Pena, 400m"; "Holotipo" [etiqueta vermelha com uma linha preta no bordo]; "Phaonia quercus/ sp.n./ S.M.P. Coelho det." (CNC). Em bom estado, 


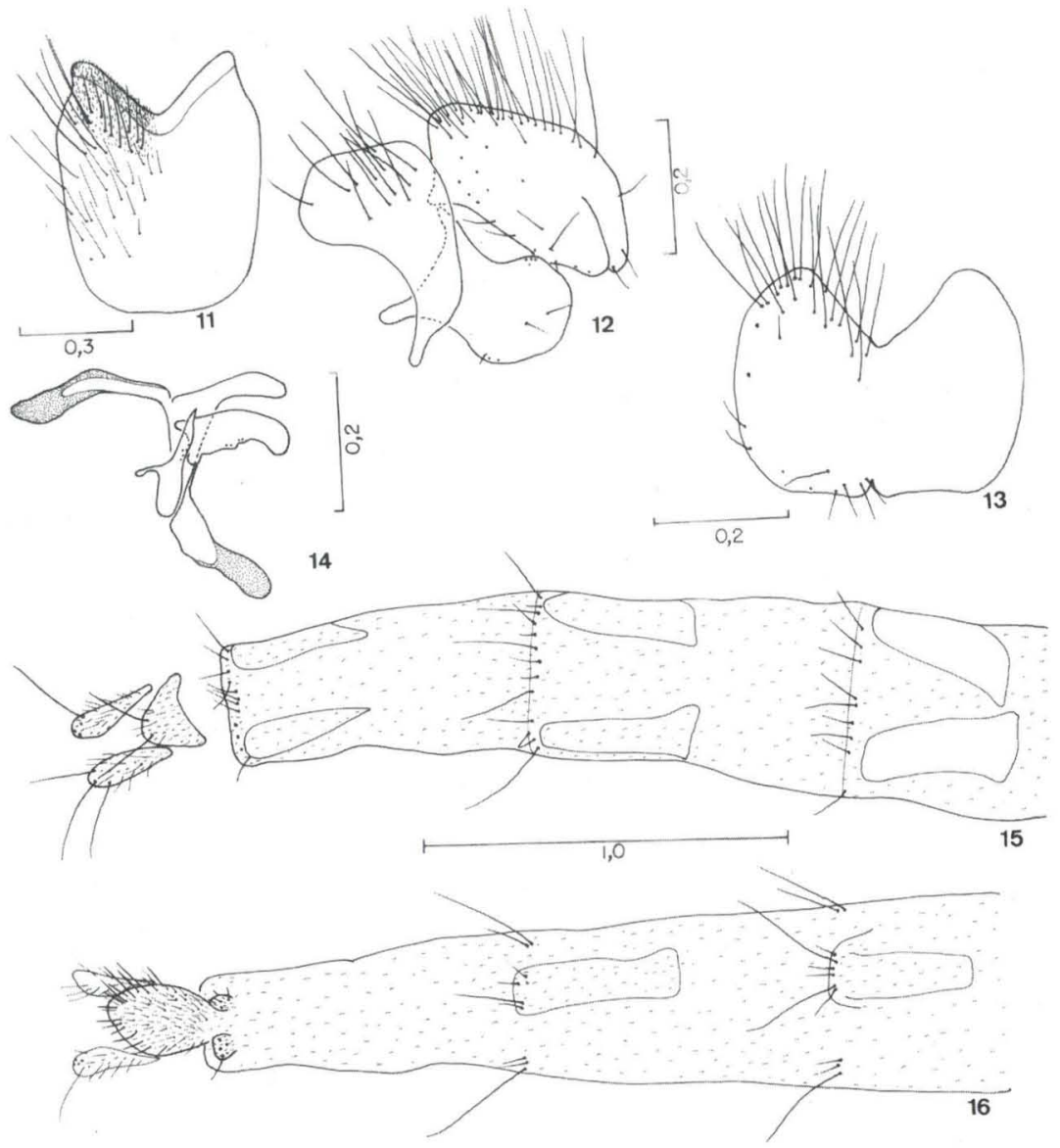

Figs 11-16. Phaonia quercus sp.n.. (11) Esternito V, vista posterior; (12) epândrio, cercos e surstilo, vista lateral; (13) cercos, vista posterior; (14) edeago e acessórios, vista lateral; (15) ovipositor, vista dorsal; (16) ovipositor, vista ventral. Escalas em milímetros.

com asas pouco danificadas e olho direito achatado; abdome dissecado, em tubinho com glicerina.

Etimologia. Do latim quercus = carvalho; alusivo ao autor de Phaonia hugonis Carvalho, 1989.

Considerações. Dois exemplares da série-tipo de Phaonia hugonis: alótipo de Quincemil, Cuzco e um parátipo de Madre de Dios, Avispas, ambos do Peru, são Phaonia quercus sp.n. e são designados parátipos desta.

Diagnose. Coloração geral castanho-escura; dc 2:3; acr 0:1; espiráculo posterior na margem PV com cílios. Macho: parâmero com a face ventral recurvada; gonópodo com a região anterior alongada e ultrapassando a largura do parâmero 
(Fig. 14). Fêmea: ovipositor com microtríquias nas membranas, tergitos e esternitos, exceto no tergito VI (Figs 15, 16).

Descrição. Coloração geral castanho-escura com polinosidade cinzenta. Frontália e probóscide castanho-escuras. Parafrontália, parafaciália, faciália e gena castanho-escuras com leve polinosidade prateada. Lúnula e palpo castanho-claros. Fêmea com ápice do palpo amarelado. Antena castanho-clara com flagelo levemente mais escuro. Fêmea, antena amarelada com escapo e pedicelo escurecidos. Tórax castanho-escuro. Escuto com quatro listras, duas medianas mais visíveis pré-suturalmente e duas laterais, mais visíveis pós-suturalmente; úmero castanho-claro. Fêmea com listras torácicas mais evidentes do que no macho e somente a união do úmero com escuto amarelado. Caliptras esbranquiçadas; balancim amarelo. Asa acastanhada com mácúlas castanho-escuras no final das veias $S c$ e $R_{1}, R_{2+3}$ e nas veias transversais anterior e posterior. Pernas castanho-escuras com articulações fêmur-tibiais amareladas; pulvilos esbranquiçados a amarelados. Abdome castanho-escuro.

Macho. 5,75mm, asa 5,42mm.

Cabeça. Olhos fortemente unidos, com esparsos cílios curtos, afastados por um espaço que mede à altura do ocelo anterior $0,12 \mathrm{~mm}$; facetas antero-internas pouco diferenciadas. Cerdas frontais em número de 10 pares iniciados no nível do pedicelo e terminados abaixo do nível do ocelo anterior; os dois primeiros pares fortes e os demais filiformes. Antena inserida abaixo da metade do olho, com flagelo cerca de 2,5 vezes o comprimento do pedicelo; arista plumosa. Parafaciália estreita, no nível do ápice do pedicelo cerca de $1 / 3$ da gena no nível inferior do olho. Palpo claviforme.

Tórax. de 2:3; acr 0:1, fraca em relação a de; duas cerdas umerais; uma pós-umeral; uma prs; duas ia; pra forte, semelhante a npl anterior; duas sa, posterior inconspícua; duas psa, posterior maior; notopleura com esparsos cílios de revestimento; npl posterior cerca de 1/2 da anterior. Escutelo com dois pares de cerdas basais, anterior medíocre; um pré-apical fraco e um apical forte, semelhante ao basal posterior. Uma pro-episternal e duas pro-epimerais. Ctpl 1:2. Um a dois cílios entre catepimero e meron. Espiráculo posterior na margem PV com cílios. Caliptra inferior cerca de 1,4 vezes a superior. Asa com nódulo radial apresentando 2-3 cílios nas faces dorsal e ventral; veia $\mathrm{M}_{1+2}$ curva em direção àR $4+5$. Fêmur I nas faces $\mathrm{D}, \mathrm{AD}$ e $\mathrm{AV}$ com uma série de cerdas em toda a face. Tíbia na face $\mathrm{A}$ nua. Tarso com garras e pulvilos pequenos, menores que o comprimento do tarsômero V. Fêmur II na face V com três cerdas basais fracas; faces D com uma cerda e PD com duas, pré-apicais e oblíquas ao plano do fêmur. Tíbia na face P com duas medianas. Tarso como no par anterior. Fêmur III na face AD com uma série de cerdas em toda face; face AV com uma série de pequenas cerdas esparsas em toda face, as duas apicais mais fortes; faces D com duas cerdas e PD com 1-2, pré-apicais e oblíquas ao plano do fêmur. Tíbia na face AD com duas cerdas medianas; face AV com 3-4 cerdas medianas, mais fracas que as anteriores; calcar fraco inserido no quinto apical. Tarso como no par anterior.

Abdome. Esternito I nu. 
Terminália. Esternito $\mathrm{V}$ quadrangular e com cerdas, exceto na região pré-basal (Fig. 11); placa cercal quadrangular, elevada superiormente, com bifurcação leve ventralmente e forte dorsalmente; surstilo pouco mais curto que a placa cercal, com cílios pré-apicais (Figs 12,13); apódema do edeago estreito; parâmero com a face ventral recurvada; gonópodo com a região anterior alongada e ultrapassando a largura do parâmero (Fig. 14).

Fêmea. 5,83-6,25mm, asa 5,67-5,92mm.

Semelhante ao macho diferindo no que segue: olhos separados por um espaço cerca de 0,32 da largura da cabeça no nível da lúnula. Triângulo ocelar com duas cerdas fortes, proclinadas e divergentes. Cerdas frontais em número de 6-7 pares, dois últimos reclinados. Vte fortes, divergentes e menores que vti que são convergentes. Parafaciália estreita, no nível do ápice do pedicelo cerca de 1/2 da gena no nível inferior do olho.

Ovipositor. Tubular, longo, semelhante ao comprimento do abdome; microtríquias presentes nas membranas, tergitos e esternitos, exceto no tergito VI (Figs $15,16)$.

Variação. Foi verificado que um exemplar de Madre de Dios, Avispas, Peru apresenta pra somente do lado direito.

Material examinado. Parátipos: PERU, Cuzco: Quincemil, 700m, 1 fêmea, 1-15.XI.1962, L. Pena leg. (CNC); Madre de Dios: Avispas, 400m, 1 fêmea, 10-20.IX.1962, L. Pena leg. (DZUP); 1 fêmea, 1-15.X.1962 (CNC). BRASIL, Rondônia: Vilhena, 1 macho, 9.X.1986, C. Elias leg., proj. Polonoroeste (DZUP).

Distribuição geográfica. PERU (Cuzco: Madre de Dios), BRASIL (Rondônia).

\section{Phaonia soratiensis sp.n.}

Figs $17-20$

Material-tipo. Holótipo macho etiquetado: "Typus!" [etiqueta vermelha]; "Bolivia/ I.09 2700m/ Sorata/ 2300m" [etiqueta verde]; "Phaonia nigripuncta/ Schnuse/[indecifrável]" [etiqueta manuscrita e dobrada no alfinete]; "Coll. W. Schnuse/ 1911-3"; "Staatl. Museum für/ Tierkunde Dresden"; "Phaonia/ nigripuncta/ Stein, 1911"; "Paralectotipo"; "Phaonia nigripuncta/ Stein, 1911 revalid./ S.M.P. Coelho det. 94"; "Holotipo"; "Phaonia soratiensis/ sp.n./ S.M.P. Coelho det." (SMT). Em bom estado; faltando o tarso mediano esquerdo e a perna posterior esquerda; abdome dissecado e em tubinho com glicerina.

Considerações. Um dos síntipos macho de Phaonia nigripuncta Stein, 1911 é Phaonia soratiensis sp.n. e é designado holótipo desta.

Etimologia. O nome específico refere-se à localidade-tipo.

Diagnose. Coloração geral castanho-escura; olhos amplamente ciliados; dc 2:3; acr 0:1; espiráculo posterior na margem PV sem cílios; fêmur II na face V com uma série de cerdas em toda a face; tíbia II na face P com três cerdas medianas; tíbia III nas faces A e PD com uma cerda sub-basal. Macho: parâmero com a face ventral nitidamente recurvada; gonópodo com a região anterior alongada e ultrapassando a largura do parâmero (Fig. 20). 

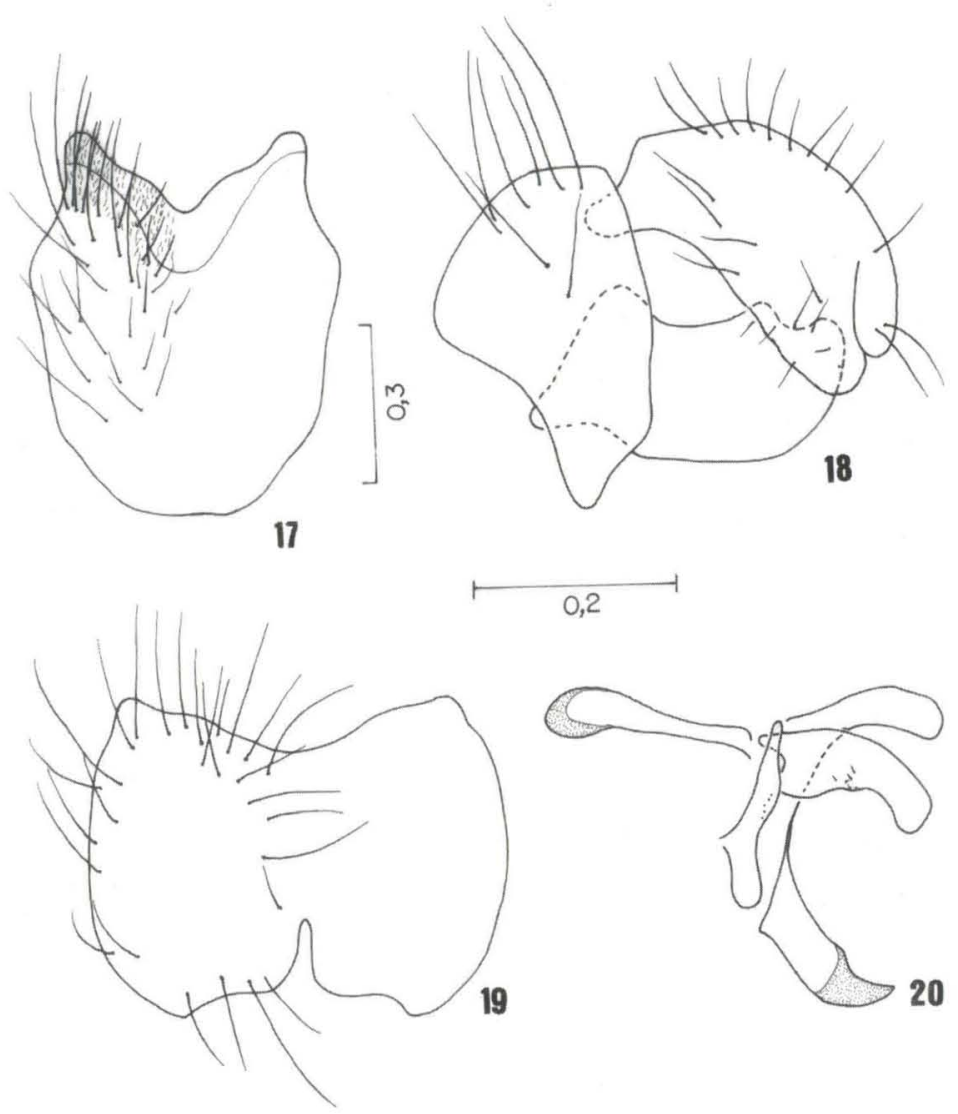

Figs 17-20. Phaonia soratiensis sp.n.. (17) Esternito V, vista posterior; (18) epândrio, cercos e surstilo, vista lateral; (19) cercos, vista posterior; (20) edeago e acessórios, vista lateral. Escalas em milimetros.

Descrição. Coloração geral castanho-escura com leve polinosidade cinzenta. Frontália, lúnula e probóscide castanho-escuras. Parafrontália, parafaciália, faciália e gena castanho-escuras com polinosidade prateada. Palpo e antena castanho-escuros. Tórax castanho-escuro. Escuto com quatro listras, duas medianas e duas laterais, mais visíveis pré-suturalmente. Caliptras esbranquiçadas; balancim amarelado. Asa amarelada com leve máculas castanho-escuras nas veias transversais anterior e posterior. Pernas castanhas com tarsos mais escuros; pulvilos esbranquiçados. Abdome castanho-escuro com polinosidade cinzenta alternada, dando aspecto xadrez.

Macho. $5,67 \mathrm{~mm}$, asa 5,00mm.

Cabeça. Olhos unidos, com muitos cílios curtos, afastados por um espaço que mede à altura do ocelo anterior cerca de $0,16 \mathrm{~mm}$; facetas antero-internas pouco diferenciadas. Cerdas frontais em número de 3-4 pares iniciados no nível do escapo e terminados no terço inferior da frontália. Antena inserida ao nível da metade do 
olho, com flagelo cerca de duas vezes o comprimento do pedicelo; arista plumosa. Parafaciália estreita, no nível do ápice do pedicelo cerca de $2 / 3$ da gena no nível inferior do olho. Palpo claviforme.

Tórax. de 2:3; acr 0:1, fraca em relação a de; três cerdas umerais; uma pós-umeral; uma prs; duas ia; pra forte, semelhante a npl anterior; uma sa; duas psa, posterior maior; notopleura com esparsos cílios de revestimento; $\mathbf{n p l}$ posterior cerca de $1 / 2$ da anterior. Escutelo com dois pares de cerdas basais, anterior medíocre; um pré-apical fraco e um apical forte, semelhante ao basal posterior. Duas cerdas pro-episternais, posterior forte e duas pro-epimerais, anterior forte. Ctpl 1:2. Catepimero, meron e espiráculo posterior na margem PV sem cílios. Caliptra inferior cerca de 1,4 vezes a superior. Asa com nódulo radial com um cílio na face ventral; veia $\mathrm{M}_{1+2}$ curva em direção à $\mathrm{R}_{4+5}$. Fêmur I nas faces $\mathrm{D}, \mathrm{AD}$ e $\mathrm{AV}$ com uma série de cerdas em toda a face. Tíbia na face A nua. Tarso com garras e pulvilos semelhantes ao comprimento do tarsômero V. Fêmur II na face V com uma série de cerdas em toda a face; faces D com uma cerda fraca e PD com duas fortes, pré-apicais e oblíquas ao plano do fềmur. Tíbia na face $\mathrm{P}$ com três cerdas medianas. Tarso como no par anterior. Fêmur III na face AD com uma série de cerdas em toda face; face AV com uma série de cerdas esparsas, com as cinco apicais fortes; faces D com duas cerdas e PD com uma, pré-apicais e oblíquas ao plano do fêmur. Tíbia na face A com uma cerda sub-basal e duas medianas; face AV com duas cerdas medianas fracas; face PD com uma cerda sub-basal e calcar forte, inserido no quinto apical. Tarso como no par anterior.

Abdome. Esternito I nu.

Terminália. Esternito V quadrangular e com cerdas, exceto pré-basalmente (Fig. 17); placa cercal retangular, elevada superiormente, com bifurcação ventralmente e face dorsal levemente côncava; surstilo pouco mais curto que a placa cercal, com cílios pré-apicais (Figs 18, 19); apódema do edeago estreito; parâmero com a face ventral nitidamente recurvada; gonópodo com a região anterior alongada e ultrapassando a largura do parâmero (Fig. 20).

Fêmea. Desconhecida.

Distribuição geográfica. Bolivin (La Paz).

AGRADECIMENTOS. Aos curadores dos Museus pelo empréstimo de material.

\section{REFERÊNCIAS BIBLIOGRÁFICAS}

CARVAlHo, C.J.B. DE. 1989. Revisão das espécies e posição sistemática de Palpibracus Rondani (Diptera, Muscidae). Revta bras. Zool. 6 (2): 325-376.

Carvalho, C.J.B. DE; M.S. Couri; A.C. Pont; D. Pamplona \& S.M. Lopes. 1993. Part II. Muscidae, p.1-201. In: C.J.B. CARVALHO (Ed.). A Catalogue of the Fanniidae and Muscidae (Diptera) of the Neotropical Region. São Paulo, Sociedade Brasileira de Entomologia,

MCAlPine, J.F. 1981. Morphology and Terminology, p.9-63. In: Manual of Neartic Diptera. Otawa, Agriculture Canada, Research Branch Monograph 27, Vol. I, VI+674p.

Recebido em 18.VI.1996; aceito em 10.IX.1997 